Vielleicht liegen mehr locale Verhăltnisse der Erscheinung zum Grunde, doch verdient sie aufgezeichnet zu werden, als eine jener mehr oder weniger heftigen Ausgleichungen von Spannung in den Gebirgsschichten, deren Endresultat die jedesmalige Form unseres Erdkorpers ist, und von welchen diese schon nach der schnellen Abnahme in der Intensität $\mathrm{zu}$ urtheilen, eine der in einem geringeren Umfang eingeschlossenen zu seyn scheint.

\title{
XXV. Ueber das Ozon.
}

(Aus cinem Briefe des Hrn. Prof. Marchand.)

Halle, d. 5. Och 1845.

$\mathbf{E}$ des sogenannten Ozons ist ohne Zweifel der von De la Rive in den Comptes rendus beschriebene, in welchem ein reiner, durch Reibungselektricităt elektrisirter Sauerstoffstrom sofort die Eigenschaften des Ozons im höchsten Maafse erlangt. Der Versuch, den ich mit Hrn. Dr. Hankel und spăter in Leipziger Laboratorium in Gegenwart des Mrn. v. Berzelius und Erdmann wiederholt habe, ist. ganz einfach der, dafs durch ein Glasrohr, in welches zwei Platindrähte einander gegenüber eingeschmolzen sind, ein reiner Sauerstoffstrom geleitet wird, während zwischen den Platindrähten elektrische Funken überspringen. Der Sauerstoff wurde aus reinem chlorsauren Kali bereitet, aus der Retorte durch ein langes Rohr mit Kalistücken gefullt geleitet, und sogleich in das Glasrohr geführt. Er konnte weder Chlor noch Wasser enthalten, der Stickstoff muiste durch den lange währenden Sauerstoffstrom verdrängt seyn, ehe der erste Funken übersprang. So wie diefs geschah, war der Sauerstoff mit den Eigenschaften des Ozons beladen. Der intensive Geruch, die Zerlegung des Jodkaliums, die Absorption durch feines Silber, welches dadurch dun- 
kel geflurbt wurde, trat sogleich cin. Aller Sauerstoff wurde nicht rom Silber absorbirt, weil die Stärke der Funken nicht hinreichte, allen Sauerstoff zu ozonisiren, jedoch ging der Ueberschufs geruchlos durch das Silber hindurch ').

XXVI. Notizen.

1) Tachträgliches über den Ausbruch des Hekla. Das Schiff, auf welches die Asche fiel (vergl. Ann., Bd. 66, S. 458), war die Schaluppe Helena. Am 21. Sept. Abends sah man eine dicke Nebelwolke sich dem Schiffe năhern, und Schiff und Segel bedeckten sich mit Asche. Das Schiff befand sich zu der Zeit unter $61^{\circ} \mathrm{N}$. Br. und $7^{\circ} 58^{\prime} \mathrm{W}$. Länge von Greenvich. Diefs giebt eine Entfernung von etwa 115 Meilen (Seemeilen? $P_{\text {.) }}$ vom Hekla, so dafs die Aschenwolke gegen 10 Meilen in einer Stunde zurückgelegt hat. Das Schiffsjournal giebt starken Wind aus NW. zu W. an (also keinen Sturm). Im Anfang October dauerte der Aschenausbruch noch immer fort. (Aus einem Briefe des Hrn. Prof. Forchhammer vom 16. Nov. 1845.)

2) Artesischer Brunnen zu Mondorf. - Dieser unter Leitung des Hrn. Kind erbohrte Brunnen hatte am 11. Sept. 1845 eine Tiefe von 671,2 Meter (2066,2 Par. Fufs). Zwei hinabgelassene Ausflufsthermometer ergaben die Temperatur am Boden desselben zu 34" $\mathrm{C}$., wăhrend ein 5 Met. tiefer Brunnen in der Nahe $11^{\circ}, 5 \mathrm{C}$, zeigte. (Compt. rend. T. XXI, p. 887.)

1) Vergl. S. 78 dienes Hefis.

$\boldsymbol{p}$. 